\title{
Causes of preterm delivery and intrauterine growth retardation in a malaria endemic region of Papua New Guinea
}

\author{
S J Allen, A Raiko, A O’Donnell, N D E Alexander, J B Clegg
}

\begin{abstract}
Aim-To identify causes of preterm delivery and intrauterine growth retardation (IUGR) in a malaria endemic region of Papua New Guinea.

Methods-Independent predictors of preterm delivery and birthweight in term infants were identified using multiple regression analysis in a prospective study of 987 singleton live births delivered in Madang Hospital.

Results-Overall, Plasmodium falciparum infection of the placenta was associated with a reduction in birthweight of 130 g. Malaria was significantly more common in primigravidae than multigravidae and probably contributed to both preterm delivery and IUGR. Maternal haemoglobin concentrations were significantly lower in malaria infected than noninfected women and reduced haemoglobin was the main determinant of preterm delivery. Poorer maternal nutritional status and smoking were associated with both prematurity and IUGR. Greater antenatal clinic attendance predicted increased birthweight in term infants.

Conclusions-Protection against malaria during pregnancy, especially in primigravidae, improved nutrition in women and discouragement of smoking would probably reduce both preterm delivery and IUGR. Greater use of existing antenatal clinics might increase birthweight in term infants.
\end{abstract}

(Arch Dis Child Fetal Neonatal Ed 1998;79:F135-F140)

Keywords: malaria; intrauterine growth retardation; Papua New Guinea; antenatal care

Institute of Molecular Medicine, John

Radcliffe Hospital,

Headington, Oxford,

OX3 9DS

$\mathrm{S} J$ Allen

A O'Donnell

J B Clegg

Papua New Guinea Institute of Medical Research,

Goroka, Papua New

Guinea

A Raiko

N D E Alexander

Correspondence to:

Dr Steve Allen.

Email:

sallen@hammer.imm.ox.ac.uk

Accepted 3 March 1998

Low birthweight complicates around $17 \%$ of all births ${ }^{1}$ and is the major risk factor for mortality in early infancy. ${ }^{2-3}$ Around $90 \%$ of all low birthweight infants are born in developing countries, ${ }^{1}$ mostly caused by intrauterine growth retardation (IUGR) rather than prematurity. ${ }^{45}$ Studies undertaken in Papua New Guinea have shown that acute diarrhoea ${ }^{6}$ and mortality from measles ${ }^{7}$ were significantly higher among low birthweight than among normal infants. Malarial infection during pregnancy is an important, and potentially preventable, environmental cause of low birthweight. The detrimental effects occur mainly in primigravidae as immunity develops during the first pregnancy and reduces infection in subsequent pregnancies. ${ }^{8}$ Although most studies have not accounted for preterm delivery in the aetiology of low birthweight, malaria is generally thought to cause it through intrauterine growth retardation rather than prematurity. ${ }^{9-10}$ The differentiation between these two mechanisms is important because the causes and outcomes of each differ. For example, neonatal mortality in preterm compared with IUGR infants was double in urban Brazil ${ }^{11}$ and nine times as high in Malawi. ${ }^{12}$

During studies on the relation between $\alpha^{+}$thalassaemia and malaria, we undertook a prospective study of singleton live births delivered at Madang Hospital on the north coast of Papua New Guinea where transmission of Plasmodium falciparum is hyperendemic and perennial. ${ }^{13}$ This provided an opportunity to identify socioeconomic and biological factors that were associated with IUGR and preterm delivery. Review of the hospital records for 1995 showed a total of 2173 deliveries of whom $315(14.5 \%)$ had not received any antenatal care. Seventy three stillbirths (3.4\%) and five maternal deaths were recorded (S Allen; unpublished data).

\section{Methods}

Permission was obtained from the Medical Research Advisory Committee of Papua New Guinea and informed consent was obtained from all mothers participating in the study. Women with live singleton infants, who had lived in Madang Province throughout their pregnancy, were recruited within 24 hours of delivery. As the detrimental effects of malaria are known to be greatest in primigravidae, ${ }^{8}$ a roughly equal number of women in each of three gravida groups (gravida 1,2 , and $\geqslant 3$ ) was obtained by recruiting all primigravidae and gravida 2 women, and the gravida $\geqslant 3$ women delivering immediately after each primigravida.
Recruitment took place during weekdays on a 24 hour basis. Ethnicity was categorised according to the region of origin of the local language spoken by the mother. In Madang Province, rural villages are mainly inhabited by Papua New Guineans of Madang ethnicity, whereas people from all regions of the country live in periurban settlements and town. The occupation of the mother and of the infant's father was categorised as either unpaid (which ployed), paid unskilled work, or paid skilled work (defined as any occupation requiring literacy).

Women attended one of several district antenatal clinics during pregnancy which dispensed chloroquine and iron and folate tabincluded subsistence farming and unem- 
Table 1 Birthweight, preterm delivery, IUGR and malaria infection according to gravidity

\begin{tabular}{|c|c|c|c|c|}
\hline & Gravida $1(n=357)$ & Gravida $2(n=237)$ & Gravida $3(n=393)$ & $P^{*}$ \\
\hline Birthweight median [IQR] (kg) & $2.72[2.44-3.00]$ & $2.93[2.63-3.26]$ & $3.09[2.76-3.39]$ & $<0.0001$ \\
\hline Preterm n $(\%) \leqslant 37$ weeks & $35(9.8)$ & $11(4.6)$ & $16(4.1)$ & 0.0027 \\
\hline Birthweight $<2500 \mathrm{~g}$ in term infants $\mathrm{n}(\%)$ & $69 / 322(21.4)$ & $25 / 226(11.1)$ & $27 / 377(7.2)$ & 0.0001 \\
\hline \multicolumn{5}{|l|}{$P$ falciparum } \\
\hline \multicolumn{5}{|l|}{ Placenta } \\
\hline frequency n (\%) & $103 / 307(33.6)$ & $55 / 208(26.4)$ & $48 / 345(13.9)$ & 0.0001 \\
\hline density† & $4.15[3.40-4.70]$ & $4.04[3.40-4.81]$ & $3.68[3.21-4.21]$ & 0.025 \\
\hline \multicolumn{5}{|l|}{ Mother } \\
\hline frequency $\mathrm{n}(\%)$ & $87 / 355(24.5)$ & $46 / 232(19.8)$ & $50 / 390(12.8)$ & 0.001 \\
\hline density† & $3.60[3.00-4.04]$ & $3.40[3.13-4.01]$ & $3.18[2.70-3.82]$ & 0.031 \\
\hline
\end{tabular}

$\star$ Kruskall-Wallis test for continuous variables and $\chi^{2}$ for categorical variables.

†Median [IQR] parasite density $\left(\log _{10}\right.$ value $)$ in infected mothers/placentas.

lets and encouraged them to attend Madang Hospital for delivery. The first measurement of maternal weight and haemoglobin, the total number of clinic visits, and obstetric and medical history were recorded from clinic cards when available. Standing height was measured after delivery with a wall mounted ruler when the mother could stand comfortably. Body mass index was calculated from a clinic weight recorded $\leqslant 28$ weeks gestation and height after delivery.

Infants were weighed at birth to the nearest $10 \mathrm{~g}$ on electronic scales (Seca, UK) by the nursing attendants and were examined by the project physician (SA) within 24 hours of delivery. Gestation was assessed by a rapid score ${ }^{14}$ and a Dubowitz assessment ${ }^{15}$ performed if the rapid score was $<7$ (equivalent to $<38.5$ weeks) or if the birthweight was $<2500 \mathrm{~g}$. Infants in whom a specific cause of abnormal intrauterine growth was suspected were excluded (gestational diabetes or hypertension, major congenital abnormality). Prematurity was defined as a Dubowitz score of $<45$ (equivalent to $<37$ weeks gestation) and IUGR as low birthweight among term infants. IUGR among preterm infants was not considered, due to a lack of birthweight standards in this population and accurate gestational age based on ultrasound examination.

A blood count (MD8, Coulter Electronics, UK) was performed and blood films prepared from maternal venous blood. The number of $P$ falciparum parasites per 200 white blood cells was counted in thick films and parasite density calculated from the measured white cell count. Thick and thin blood films were made from the cut maternal surface of the placenta and parasite density was calculated from the number of parasites per 100 high power fields, assuming that each field contains $0.002 \mu \mathrm{l}$ of blood.

Continuous variables tended to have skewed distributions and, therefore, median values with the interquartile range (IQR) are quoted. Two main analyses were performed. Determinants of preterm delivery were investigated using logistic regression analysis in all infants with gestation (preterm $<37$ weeks or term $\geqslant 37$ weeks) as the dependent variable. All infants delivered $\geqslant 28$ weeks gestation and, therefore, only information relating to antenatal clinic visits $\leqslant 28$ weeks gestation was included in the analysis. Determinants of birthweight in term infants were investigated using multiple regression analysis. For both analyses, forward stepwise regression analysis was performed to identify factors which independently predicted the outcome variable.

\section{Results}

Nine hundred and eighty seven singleton live born infants were recruited between July 1994 and January 1996. Birthweight in preterm infants ranged from 0.78 to $3.00 \mathrm{~kg}$ and $59 / 62$ (95\%) were low birthweight. Overall, the relative risk $(95 \%$ confidence interval) of low birthweight for primigravidae compared with gravida 2 women was 2.23 (1.43-3.50), $\mathrm{p}<0.001$, and compared with all multigravidae it was 2.83 (2.00-4.01), p<0.0001. BMI was calculated in 466 women and $29(6.2 \%)$ were underweight $\left(<20 \mathrm{~kg} / \mathrm{m}^{2}\right)$. BMI was strongly correlated with weight during pregnancy (Pearson's $r=0.91 ; 95 \%$ CI $0.89-0.92)$, but weakly correlated with height $(\mathrm{r}=0.09 ; 95 \%$ CI 0.01-0.17).

\section{MALARIA}

The prevalence of prematurity, IUGR, and malaria infection of both the placenta and maternal blood at delivery were significantly higher in primigravidae than multigravidae (table 1). Although numbers were small, no evidence of a decrease in birthweight or increase in preterm deliveries was observed in gravida $\geqslant 6$. Median (IQR) birthweight was $2.85 \mathrm{~kg}(2.50-3.10)$ when the placenta was infected, and when not, $2.98 \mathrm{~kg}$ (2.67-3.27; $\mathrm{p}<0.0001)$. Median maternal haemoglobin after delivery when the placenta was infected measured $101 \mathrm{~g} / 1$ (91-110) and when not 107 $\mathrm{g} / 1$ (94-118; $\mathrm{p}<0.001)$. Median maternal haemoglobin after delivery was similar in each gravida group, although there was a tendency for more primigravidae than multigravidae to have haemoglobin values $<100 \mathrm{~g} / 1$ (41.6 vs $35.9 \% ; \mathrm{p}=0.10)$. Placental infection was highly correlated with maternal peripheral blood infection $(p<0.001)$ and the differences in birthweight and maternal haemoglobin were similar if maternal infection rather than placental infection was analysed. Haemoglobin during pregnancy tended to decline as gestation increased $(n=392 ; r=-0.10 \quad(95 \%$ CI -0.20 to 0.00 ). Haemoglobin values during pregnancy cannot be compared with values after delivery as different methods of measurement were used.

The prevalence of placental and maternal peripheral blood parasitaemia was similar in those who had and had not taken chloroquine during pregnancy $(186 / 791$ (23.5\%) vs $20 / 68$ 


\section{Key points}

- In coastal Papua New Guinea, roughly a third of low birthweight infants were preterm and two thirds were growth retarded, term infants

- Protection from malaria during pregnancy, especially in primigravidae, may prevent both IUGR and preterm delivery

- A reduced maternal haemoglobin concentration was the main determinant of preterm birth

- Prevention of smoking during pregnancy, improved nutrition in girls and women, and increased antenatal care may also prevent low birthweight in this region

(29.4\%), $\mathrm{p}=0.35$ and $167 / 900(18.6 \%)$ vs $15 / 76(19.7 \%), p=0.92$, respectively). The density of parasitaemia in each site was not related to chloroquine prophylaxis. However, median (IQR) maternal haemoglobin concentrations after delivery were significantly greater in women who gave a history of chloroquine prophylaxis $(\mathrm{n}=862,105 \mathrm{~g} / 1(93-117))$ than in those who did not $(\mathrm{n}=61,99 \mathrm{~g} / 1(82-107)$; $p=0.0002)$. The usage of chloroquine and iron/folate was highly correlated $(p<0.001)$ and similar differences in haemoglobin concentrations were observed if iron/folate rather than chloroquine usage was analysed.
DETERMINANTS OF PRETERM DELIVERY AND BIRTHWEIGHT IN TERM INFANTS

In univariate analysis both preterm delivery and IUGR were significantly associated with lower BMI, lower gravidity, the mother smoking during pregnancy, and working in a garden (table 2). Paternal employment in skilled work was negatively associated with prematurity and IUGR. Other predictors of prematurity were reduced maternal haemoglobin both during and after pregnancy and no chloroquine and iron/folate. Gestation (beyond 37 weeks) had the strongest association with birthweight in term infants (table 2) (fig 1). The mother or father in paid employment, greater maternal height, and a greater number of antenatal clinic visits were associated with increased birthweight in term infants whereas malaria infection at delivery were associated with IUGR. Maternal age was not significantly associated with birthweight when gravidity was included as a confounder. Only haemoglobin measured $\leqslant 28$ weeks gestation were included in the analysis of haemoglobin during pregnancy and these measurements had been performed at a similar gestation in preterm and term infants (median 22.5 and 23.0 weeks, respectively; $\mathrm{p}=0.62)$. The gestation at which maternal weight had been measured was also similar for preterm and term infants (median 22.9 and 20.9 weeks respectively; $p=0.22$ ). Median (IQR) birthweight was significantly greater in

Table 2 Determinants of prematurity and birthweight in term infants $\dagger$

\begin{tabular}{|c|c|c|c|}
\hline Factor & All women & $\begin{array}{l}\text { OR }(95 \% \text { CI) for preterm } \\
\text { delivery }\end{array}$ & $\begin{array}{l}\text { Estimated effect on } \\
\text { birthweight }(\mathrm{g}) \text { in term } \\
\text { infants }(95 \% \mathrm{CI})\end{array}$ \\
\hline \multicolumn{4}{|l|}{ Socioeconomic } \\
\hline \multicolumn{4}{|l|}{ Mother } \\
\hline paid work & $89 / 984(9.0)$ & $0.68(0.24-1.92)$ & $100(0 \text { to } 200)^{\star}$ \\
\hline work in garden & $513 / 984(52.1)$ & $1.73(1.01-2.95)^{\star}$ & $-141(-199 \text { to }-84)^{\star \star \star}$ \\
\hline schooling (years) (IQR) & $9856(2-8)$ & $0.95(0.88-1.02)$ & $7(-2$ to 15$)$ \\
\hline \multicolumn{4}{|l|}{ Father } \\
\hline paid work & $471 / 982(48.0)$ & $0.62(0.37-1.06)$ & $144(87 \text { to } 202)^{\star \star \star}$ \\
\hline skilled work & $329 / 982(33.5)$ & $0.41(0.21-0.79)^{\star \star}$ & $147(87 \text { to } 207)^{\star \star \star}$ \\
\hline \multicolumn{4}{|l|}{ Maternal biological } \\
\hline Age (years) (IQR) & $81623(20-27)$ & $0.96(0.91-1.02)$ & $21(15 \text { to } 27)^{\star \star \star}$ \\
\hline Gravidity (IQR) & $9871(0-3)$ & $0.79(0.66-0.95)^{\star \star}$ & $69(53 \text { to } 84)^{\star \star \star}$ \\
\hline Height (cm) (IQR) & $9631.54(1.50-1.58)$ & $0.034(0.00024-4.66)$ & $15(10 \text { to } 21)^{\star \star \star}$ \\
\hline BMI & $46623.6(21.8-25.6)$ & $0.79(0.66-0.94)^{\star \star}$ & $39(29 \text { to } 48)^{\star \star \star}$ \\
\hline Miscarriage or stillbirth㧊 & $107 / 630(17.0)$ & $0.84(0.29-2.49)$ & $-35(-130$ to 60$)$ \\
\hline 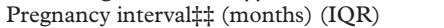 & $41422(14-35)$ & $1.003(1.00-1.01)$ & $-1(-3$ to 1$)$ \\
\hline \multicolumn{4}{|l|}{$\mathrm{Hb}(\mathrm{g} / \mathrm{l})$} \\
\hline during pregnancy (IQR)‡†† & $39298(81-108)$ & $0.64(0.46-0.89)^{\star \star}$ & $13(-12$ to 38$)$ \\
\hline after delivery (IQR) & $924105(92-116)$ & $0.70(0.60-0.82)^{\star \star \star}$ & $14(-1$ to 30$)$ \\
\hline \multicolumn{4}{|l|}{$P$ falciparum } \\
\hline placenta & $206 / 860(24.0)$ & $1.81(0.98-3.34)$ & $-145(-218 \text { to }-73)^{\star \star \star}$ \\
\hline mother & $183 / 977(18.7)$ & $1.71(0.95-3.05)$ & $-128(-203 \text { to }-53)^{\star \star}$ \\
\hline Gestation at delivery (IQR) & $98739(38-40)$ & - & $158(134-181)^{\star \star \star}$ \\
\hline \multicolumn{4}{|l|}{ Antenatal } \\
\hline Attended clinic $\$$ & $917 / 986(93.0)$ & $0.62(0.34-1.11)$ & $126(8 \text { to } 244)^{\star}$ \\
\hline Number of clinic visits (IQR) & $6805(4-7)$ & - & $39(26 \text { to } 51)^{\star \star \star}$ \\
\hline Gestation at first clinic visit $\int$ (weeks) (IQR) & $78326(22-31)$ & $0.95(0.87-1.04)$ & $-1(-5$ to 4$)$ \\
\hline \multicolumn{4}{|l|}{ Drugs: } \\
\hline chloroquine (IQR) & $908 / 986(92.1)$ & $0.32(0.16-0.63)^{\star \star}$ & $103(-9$ to 216$)$ \\
\hline iron/folate & $884 / 986(89.7)$ & $0.40(0.21-0.77)^{\star}$ & $-8(-106$ to 90$)$ \\
\hline Smoker & $102 / 987(10.3)$ & $2.49(1.30-4.77)^{\star}$ & $-137(-235 \text { to }-40)^{\star \star}$ \\
\hline Infant Male sex & $510 / 987(51.7)$ & $0.93(0.56-1.56)$ & $70(12 \text { to } 128)^{\star}$ \\
\hline
\end{tabular}

tValues for continuous variables are number, median and (IQR) and for categories number (\%). Statistics are results of univariate regression analysis. The OR for preterm delivery and the estimated effect on birthweight $(\mathrm{g})$ in term infants relates to the presence of a categorical variable or a unit increase in a continuous variable. ${ }^{\star} \mathrm{p} \leqslant 0.05,{ }^{\star \star} \mathrm{p}<0.01,{ }^{\star \star \star} \mathrm{p}<0.001$.

$\ddagger$ Only values recorded $\leqslant 28$ weeks gestation included.

t+Gestation at time of measurement included as a confounder in the regression analysis.

\#Multigravidae only; pregnancy interval is the period from the previous birth to conception of the current pregnancy.

\Only values recorded $\leqslant 28$ weeks gestation included for the analysis of preterm delivery. 495/852 (58.1\%) women had attended clinic $\leqslant 28$ weeks gestation and median (IQR) gestation at booking was $23(20-25)$ weeks in these women. 


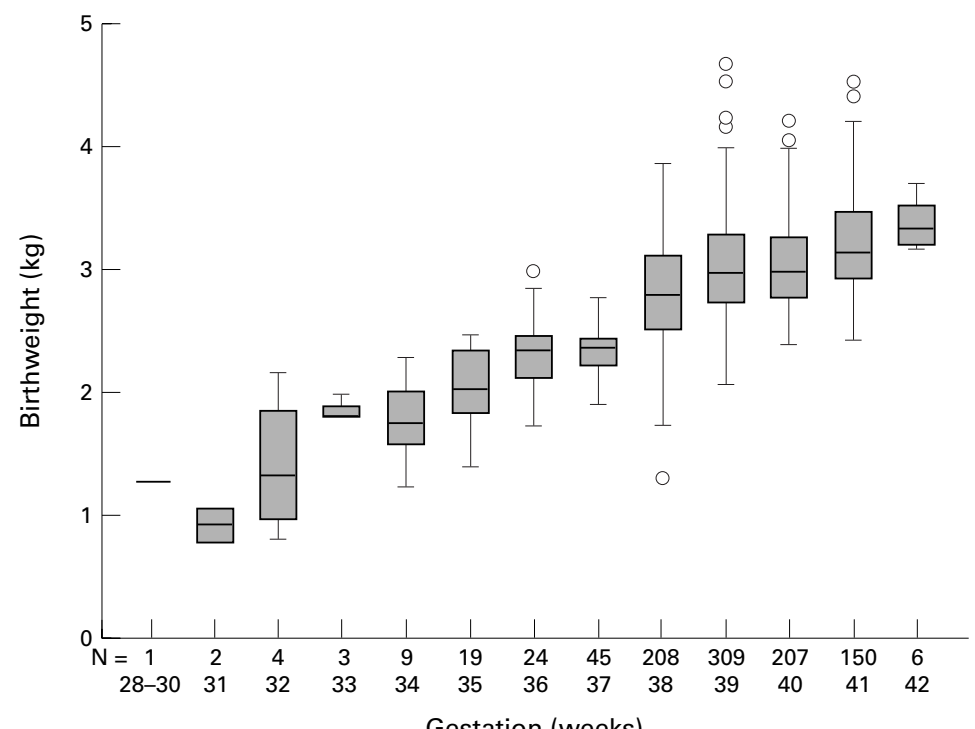

Figure 1 Birthweight according to gestation (987 infants). Median values are indicated by dense band; box represents interquartile range, with whiskers extending up to $1.5 \times I Q R$ from upper or lower limits of box; open circles represent infants with birthweights beyond this range.

boys $(2.99 \mathrm{~kg}(1.31-4.66)$ than girls $(2.90$ (1.90-4.22); $\mathrm{p}=0.0076)$.

Birthweight was greater in the infants of women living in Madang town (median (IQR) $3.03 \mathrm{~kg}(2.69-3.36))$ than in rural villages (2.88 (2.54-3.20)) or settlements (2.92 (2.63$3.24) ; \mathrm{p}<0.001)$, but residence was not related to gestation $(p=0.86)$. Birthweight was greater in the infants of Highland women $(3.18 \mathrm{~kg}$ $(2.76-3.49))$ than all other women $(p=0.011$; other coastal regions 3.03 (2.70-3.38), Madang 2.89 (2.56-3.18), and Sepik 2.90 (2.62$3.21)$ ). A greater proportion of Highland women lived in town $(15,47 \%)$ vs $190(21 \%)$, respectively; $\mathrm{p}=0.001$ ) and a lower proportion had worked in gardens $(13,34 \%)$ vs 500 $(53 \%)$, respectively; $\mathrm{p}=0.024)$. Median (IQR) gestation in women of Highland ethnicity was 39 (39-40) weeks and was similar to that in all other women (39 (38-40); $\mathrm{p}=0.22)$. Highland women had greater haemoglobin concentra-

Table 3 Independent predictors of preterm delivery in multiple logistic regression analysis $(n=923)$

\begin{tabular}{llr}
\hline Variable & OR $(95 \%$ CI $)$ & p Value \\
\hline Maternal haemoglobin after delivery $(\mathrm{g} / \mathrm{l})$ & $0.97(0.96-0.99)$ & $<0.001$ \\
Smoking & $2.44(1.18-5.05)$ & 0.024 \\
Gravidity & $0.82(0.68-0.99)$ & 0.026 \\
Chloroquine & $0.41(0.19-0.92)$ & 0.041 \\
\hline
\end{tabular}

Odds ratios represent the risk of preterm delivery for a $10 \mathrm{~g} / 1$ increase in maternal haemoglobin or the presence of a categorical variable. BMI was available for 466 women only and was not included in this model (see text).

Table 4 Independent predictors of birthweight in term infants in multiple linear regression analysis $(n=653)$

\begin{tabular}{lcc}
\hline Variable & $\begin{array}{l}\text { Estimated effect on birthweight } \\
(\mathrm{g})(95 \% \mathrm{CI})\end{array}$ & p Value \\
\hline Gestation (weeks) & $127(101$ to 153$)$ & $<0.001$ \\
BMI $\left(\mathrm{kg} / \mathrm{m}^{2}\right)$ & $21(19$ to 36$)$ & $<0.001$ \\
Gravidity & $48(32$ to 65$)$ & $<0.001$ \\
Number of antenatal clinic visits & $33(21$ to 45$)$ & $<0.001$ \\
Maternal height $(\mathrm{cm})$ & $10(5$ to 16$)$ & $<0.001$ \\
Male infant & $84(27$ to 141$)$ & 0.004 \\
Smoking & $-120(-218$ to -22$)$ & 0.016 \\
\hline
\end{tabular}

The estimated effect on birthweight is the change in birthweight $(\mathrm{g})$ for the presence of a categorical predictor variable or a unit increase in a continuous variable. tions both during pregnancy and after delivery than other women-for example, median (IQR) haemoglobin after delivery $115 \mathrm{~g} / 1$ (94127) vs $105 \mathrm{~g} / 1$ (92-116), respectively; $\mathrm{p}=0.001$. Smoking was more common among Highland women, but all other factors, including anthropometric measurements and parasitological indices, were similar.

Variables with an independent and significant association with prematurity identified by forward stepwise logistic regression analyses (excluding BMI) are shown in table 3. When only the 466 records with a value for BMI were analysed, only maternal haemoglobin after delivery (OR=0.96, 95\% CI 0.94-0.99; $\mathrm{p}=0.005)$ and $\mathrm{BMI} \quad(\mathrm{OR}=0.84,95 \% \quad \mathrm{CI}$ $0.70-1.01 ; \mathrm{p}=0.042)$ were significantly predictive of preterm delivery. Similarly, factors independently associated with birthweight are shown in table 4 . The same factors were identified when BMI was omitted from the analysis and women without a BMI value were included. In multigravidae a previous miscarriage or stillbirth was also independently associated with birthweight $(\beta=-127 \mathrm{~g} ; 95 \%$ CI-222 to-31; $\mathrm{p}=0.009$ ).

\section{Discussion}

Assessment of the impact of malaria on the outcome of pregnancy is complicated because the greatest incidence of infection occurs during the second trimester, and placental and peripheral blood parasitaemia may have resolved by the time of delivery. ${ }^{8}$ This may account for the apparent absence of an effect of malaria infection at delivery on birthweight in a small study of hospital deliveries in the Sepik region of Papua New Guinea. ${ }^{16}$ Malaria is an environmental factor which affects primigravidae more than multigravidae and the risk of low birthweight among primigravidae relative to multigravidae may reflect more accurately the impact of malaria during pregnancy than the presence of either placental or maternal peripheral blood parasitaemia at delivery. ${ }^{17}$ Both malaria infection at delivery and low birthweight were greatly increased in primigravidae compared with multigravidae in this study and this pattern is similar to that reported in African women. ${ }^{8}$ Overall, malaria infection of the placenta was associated with a reduction in birthweight of $130 \mathrm{~g}$ - a difference similar to that found in Africa ${ }^{8}$ and Thailand. ${ }^{18}$ Low gravidity was an independent predictor of both preterm delivery and IUGR in multiple regression analysis, suggesting that malaria infection contributed to both outcomes.

In contrast to developed countries, neonatal mortality in preterm infants in developing countries remains high ${ }^{11}$ and has been reported to be much higher in preterm than growth retarded infants. ${ }^{11}{ }^{12}$ Although acute malaria has been observed to cause preterm labour, ${ }^{2021}$ the few epidemiological studies which have considered malaria as a cause of prematurity have produced conflicting results. Maternal infection was not associated with preterm delivery in Thailand ${ }^{19}$ or in a small study in the Sepik region of Papua New Guinea. ${ }^{22}$ Although gestational age was not 
related to either placental or maternal parasitaemia at delivery in the Ivory Coast, maternal antibody titres against $P$ falciparum were significantly higher in mothers of preterm than term infants. ${ }^{10}$ Placental and cord blood parasitaemia were more common in preterm than term infants in Malawi, ${ }^{23}$ and parasitaemia and maternal anaemia were associated with preterm delivery in Mozambique. ${ }^{24}$

In this study a third of all low birthweight infants were preterm and reduced maternal haemoglobin after delivery was the factor most strongly predictive of preterm delivery. Malaria is a major cause of maternal anaemia in this region and the highest rate of preterm deliveries occurred among anaemic women in a previous study in Madang. ${ }^{25}$ Hookworm infection, although common, does not cause anaemia in this population because worm burdens are low. ${ }^{26}$ Homozygous $\alpha^{+}$-thalassaemia is common in this population and, although associated with mild anaemia, it prevents severe malarial anaemia in children. ${ }^{27}$ The impact of $\alpha^{+}$-thalassaemia on maternal anaemia and the outcome of pregnancy will be reported separately.

The prevention of malaria increased maternal haemoglobin concentrations in several studies. ${ }^{28}$ Chloroquine prophylaxis increased haemoglobin in this study and in the previous study of Madang women. ${ }^{25}$ The finding that chloroquine prophylaxis was a significant independent predictor of delivery at term needs to be interpreted with caution as women delivering at term would have had greater opportunity to take this drug than those delivering before term. As observed before, ${ }^{29}$ chloroquine did not reduce either placental or maternal peripheral blood infection at delivery. The choice of an alternative antimalarial drug to chloroquine depends on several factors, and randomised control trials assessing various regimens have been reviewed recently. ${ }^{28}$ Additional strategies to prevent malaria during pregnancy, such as insecticide impregnated bed nets, ${ }^{30}$ and the targeting of interventions to primigravidae, should also be considered.

Poor maternal nutritional status was reported to be associated with reduced birthweight in previous studies in the Highlands ${ }^{31}$ and coastal regions of Papua New Guinea. ${ }^{32} 33$ In this study lower BMI was an independent predictor of both preterm delivery and IUGR and lower maternal height were also independently associated with IUGR. BMI serves as a measure of chronic energy deficiency and, as expected, was highly correlated with maternal weight but not height. ${ }^{34}$ Maternal malnutrition was probably underestimated in this study because BMI was calculated from weight measured during pregnancy rather than from pre-pregnancy weight which would be expected to be lower. Low maternal height is a consequence of growth failure during childhood and adolescence.

Gestation was the strongest predictor of increased birthweight in term infants and this suggests that interventions which prolong gestation may increase birthweight in term infants as well as reduce preterm delivery. Greater birthweight among Highland women delivering on the coast than indigenous coastal mothers has been noted before and considered to be due, in part, to longer gestation. ${ }^{31}{ }^{32}$ Gestation at delivery was not related to ethnic origin in this study and better intrauterine growth in Highland women was likely to be a consequence of their more favourable economic status. Around $70 \%$ of women living in Madang villages receive at least some antenatal care. ${ }^{25}$ Antenatal clinic attendance was negatively associated with IUGR and this association was independent of chloroquine prophylaxis and markers of family wealth. Previous studies have shown increased perinatal mortality among infants of women who do not receive any antenatal care $^{32}$ and lower average birthweight in village than hospital deliveries. ${ }^{22}$ Smoking has been identified as the most important single cause of low birth weight in developed countries $^{9}$ and was significantly and independently associated with both preterm delivery and IUGR in this study.

In summary, we have identified several determinants of prematurity and IUGR which could be modified by community health services in Madang Province in an attempt to reduce infant mortality. Integrated antenatal care should be promoted and focus on effective measures to prevent malaria, especially important in primigravidae and for the prevention of pregnancy anaemia. Improving nutritional status in girls and young women, and during pregnancy, and discouraging smoking, would also be expected to prevent low birthweight in this population.

We are indebted to women delivering in the "haus karim" of Madang hospital for their participation, the ward nursing staff, Willie Deppsone for help with recruitment and Dr Michael Alpers for helpful guidance.

This project is part of a multicentre study of the effects of haemoglobin and red cell genetic variants on malaria in the South Pacific region and was funded by The Wellcome Trust grant No 035893 .

1 World Health Organisation. Maternal health and safe motherhood programme. $L B W$-a tabulation of available information. Geneva: World Health Organisation, 1992.

2 Willcox AJ, Russell IT. Birthweight and perinatal mortality: II. On weight-specific mortality. Int $\mathcal{f}$ Epidemiol 1983;12:319-25.

3 McCormick MC. The contribution of low birth weight to infant mortality and childhood morbidity. $N$ Engl $\mathcal{F}$ Med 1985;312:82-90.

4 Belizán JM, Lechtig A, Villar J. Distribution of low-birth weight babies in developing countries. Am f Obstet Gynecol 1978;132:704-5.

5 Villar J, Belizán JM. The relative contribution of prematurity and fetal growth retardation to low birth weight in developing and developed societies. Am f Obstet Gynecol 1982;143:793-8.

6 Bukenya GB, Barnes T, Nwokolo N. Low birthweight and acute childhood diarrhoea: evidence of their association in an urban settlement of Papua New Guinea. Ann Trop Paediatr 1991;11:357-62.

7 Coakley KJ, Coakley CA, Spooner V, Smith TA, Javati A, Kajoi M. A review of measles admissions and deaths in the Kajoi M. A review of measles admissions and deaths in the PNG Med $₹$ 1991;34:6-12.

8 Brabin BJ. An analysis of malaria in pregnancy in Africa. Bull WHO 1983;61:1005-16.

9 Kramer MS. Determinants of low birth weight: methodological assessment and meta-analysis. Bull WHO 1987;65:663-737

10 Reinhardt MC, Ambroise-Thomas P, Cavallo-Serra R, Meylan C, Gautier R. Malaria at delivery in Abidjan. Helv Paediatr Acta 1978;33(suppl 41):65-84.

11 Barros FC, Huttly SRA, Victora CG, Kirkwood BR, Vaughan JP. Comparison of the causes and consequences of prematurity and intrauterine growth retardation: a lonof prematurity and intrauterine growth retardation: a lon-
gitudinal study in Southern Brazil. Pediatrics 1992;90:238gitudir. 
12 Bloland P, Slutsker L, Steketee RW, Wirima JJ, Heymann DL, Breman JG. Rates and risk factors for mortality dur-
ing the first two years of life in rural Malawi. Am 7 Trop Med Hyg 1996;55:82-6.

13 Cattani JA, Tulloch JL, Vrbova H, et al. The epidemiology of malaria in a population surrounding Madang, Papua New Guinea. Am F Trop Med Hyg 1986;35:3-15.

14 Parkin JM, Hey EN, Clowes JS. Rapid assessment of gestational age at birth. Arch Dis Child 1976;51:259-63.

15 Dubowitz LMS, Dubowitz V, Goldberg G. Clinical assessment of gestational age in the newborn infant. $\mathcal{F}$ Paediatr 1970;77:1-10

16 Desowitz RS, Alpers MP. Placental Plasmodium falciparum parasitaemia in East Sepik (Papua New Guinea) women of different parity: the apparent absence of acute effects on mother and foetus. Ann Trop Med Parasitol 1992;86:95102 .

17 Brabin B. An assessment of low birthweight risk in primiparae as an indicator of malaria control in pregnancy. primiparae as an indicator of mat

18 Nosten F, ter Kuile F, Maelankirri L, Decludt B, White NJ. Malaria during pregnancy in an area of unstable endemicity. Trans R Soc Trop Med Hyg 1991;85:424-29.

19 Nosten F, ter Kuile F, Maelankiri L, et al. Mefloquine prophylaxis prevents malaria during pregnancy: a doubleblind, placebo-controlled study. F Infect Dis 1994;169:595603.

20 Gilles HM, Lawson JB, Sibelas M, Voller A, Allan N Malaria, anaemia and pregnancy. Ann Trop Med Parasitol 1969;63:245-63.

21 Woodruff AW, Adamson EA, El Suni A, Maughan TS, Kaku M, Bundru N. Infants in Juba, Southern Sudan: the first six months of life. Lancet 1983;ii:262-4.

22 Garner P, Dubowitz L, Baea M, Lai D, Dubowitz M, Heywood P. Birthweight and gestation of village deliveries in Papua New Guinea. F Trop Pediatr 1994;40:37-40.

23 Steketee RW, Wirima JJ, Hightower AW, Slutsker L, Heymann DL, Breman JG. The effect of malaria and malaria prevention in pregnancy on offspring birthweight, malaria prevention in pregnancy on offspring birthweight, Malawi. Am 7 Trop Med Hyg 1996;55:33-41.
24 Osman NB, Folgosa E, Bergstrom S. An incident casereferent study of threatening preterm birth and genital referent study of threatening preterm birt
infection. F Trop Pediatr 1995;41:267-72.

25 Brabin BJ, Ginny M, Sapau J, Galme K, Paino J. Consequences of maternal anaemia on the outcome of pregnancy in a malaria endemic area in Papua New Guinea. Ann Trop Med Parasitol 1990;84:11-24.

26 Pritchard DI, Quinnell RJ, Moustafa M, et al. Hookworm (Necator americanus) infection and storage iron depletion. Trans R Soc Trop Med Hyg 1991;85:235-8.

27 Allen SJ, O'Donnell A, Alexander NDE, et al. $\alpha^{+}-$ thalassaemia protects children against disease caused by other infections as well as malaria. Proc Natl Acad Sci 1997;94:14736-41

28 Garner P, Brabin B. A review of randomised controlled trials of routine antimalarial drug prophylaxis during pregnancy in endemic malarious areas. Bull WHO pregnancy in

29 Brabin BJ, Brabin L, Ginny M, et al. Failure of chloroquine prophylaxis for falciparum malaria in pregnant women in prophylaxis for falciparum malaria in pregnant women in 1990;84:1-9.

30 D'Alessandro U, Langerock P, Bennett S, Francis N, Cham Kabir, Greenwood BM. The impact of a national impregnated bed net programme on the outcome of pregnancy in primigravidae in The Gambia. Trans Roy Soc Trop Med Hyg 1996; 90:487-92

31 Primhak RA, MacGregor DF. Ethnic and environmental factors affecting fetal growth in Papua New Guinea. Ann Hum Biol 1991;18:235-43.

32 Klufio CA, Kariwiga G, MacDonald R. Normal birthweight at Port Moresby General Hospital: a retrospective survey of normal term births to determine birthweight distribution. PNG Med F 1992;35:10-16.

33 Klufio CA, Kariwiga G. A comparison of unbooked mothers delivering at Port Moresby General Hospital with mothers seen antenatally: socioeconomic and reproductive characteristics. PNG Med $\mathcal{F}$ 1992;35:3-9.

34 Shetty PS, James WPT. Body mass index. FAO Food and Nutrition Paper. Food and Agriculture Organization of the United Nations, Rome, 1994. 